\title{
BMJ
}

\section{Mortality from pandemic A/H1N1 2009 influenza in England: public health surveillance study}

Liam J Donaldson, chief medical officer for England, ${ }^{1}$ Paul D Rutter, clinical adviser, ${ }^{1}$ Benjamin M Ellis, clinical
adviser, ${ }^{1}$ Felix E C Greaves, clinical adviser, ${ }^{1}$ Oliver T Mytton, clinical adviser, ${ }^{1}$ Richard G Pebody, consultant medical epidemiologist, ${ }^{2}$ lain E Yardley, clinical adviser ${ }^{1}$

\section{ABSTRACT}

Objective To establish mortality from pandemic A/H1N1

2009 influenza up to 8 November 2009.

Design Investigation of all reported deaths related to pandemic A/H1N1 in England.

Setting Mandatory reporting systems established in acute hospitals and primary care.

Participants Physicians responsible for the patient. Main outcome measures Numbers of deaths from influenza combined with mid-range estimates of numbers of cases of influenza to calculate age specific case fatality rates. Underlying conditions, time course of illness, and antiviral treatment.

Results With the official mid-range estimate for incidence of pandemic $\mathrm{A} / \mathrm{H} 1 \mathrm{~N} 1$, the overall estimated case fatality rate was 26 (range 11-66) per 100000 . It was lowest for children aged 5-14 (11 (range 3-36) per 100000$)$ and highest for those aged $\geq 65$ (980 (range 300-3200) per $100000)$. In the 138 people in whom the confirmed cause of death was pandemic $A / H 1 N 1$, the median age was 39 (interquartile range 17-57). Two thirds of patients who died $(92,67 \%)$ would now be eligible for the first phase of vaccination in England. Fifty (36\%) had no, or only mild, pre-existing illness. Most patients (108, 78\%) had been prescribed antiviral drugs, but of these, 82 (76\%) did not receive them within the first 48 hours of illness.

Conclusions Viewed statistically, mortality in this pandemic compares favourably with 20th century influenza pandemics. A lower population impact than previous pandemics, however, is not a justification for public health inaction. Our data support the priority vaccination of high risk groups. We observed delayed antiviral use in most fatal cases, which suggests an opportunity to reduce deaths by making timely antiviral treatment available, although the lack of a control group limits the ability to extrapolate from this observation. Given that a substantial minority of deaths occur in previously healthy people, there is a case for extending the vaccination programme and for continuing to make early antiviral treatment widely available.

\section{INTRODUCTION}

On 11 June 2009 the World Health Organization formally confirmed the first pandemic of influenza for
40 years. ${ }^{1}$ The novel pandemic A/H1N1 virus, which contains swine, avian, and human elements, ${ }^{2}$ began to cause illness in the United Kingdom about a month ${ }^{3}$ after it first emerged in Mexico ${ }^{4}$ in March 2009.

In the UK, influenza related mortality is traditionally calculated with the national system of vital statistics. This is achieved by analysing death certificates or by deriving a statistical estimate of influenza related mortality based on all cause "excess mortality." When numbers are small, measures of excess mortality are of limited use in estimating deaths from influenza in adults. Estimates based on death certificates might be subject to a delay of weeks and depend on the accuracy and completeness of death certificates, which are known to be unreliable. ${ }^{6}$ So far, mortality associated with pandemic A/H1N1 2009 influenza (here after referred to as pandemic $\mathrm{A} / \mathrm{H} 1 \mathrm{~N} 1$ ) has been reported with variable completeness worldwide ${ }^{7}$ and in particular subgroups, including inpatients, ${ }^{8}$ patients in critical care ${ }^{9-11}$ pregnant women, ${ }^{12}$ and children. ${ }^{13}$

To obtain timely and accurate information on all deaths, the chief medical officer for England instigated an investigation of every death in England considered to be related to pandemic $\mathrm{A} / \mathrm{H} 1 \mathrm{~N} 1$. We analysed these data, describing all reported deaths related to pandemic A/H1N1 infection in England by 8 November 2009 .

\section{METHODS}

All acute hospitals in England's National Health Service (NHS) report their daily bed capacity to the Department of Health during winter months. With the onset of the pandemic, from the 7 July 2009 acute hospitals were asked to use this system to report suspected and confirmed deaths from pandemic A/H1N1. On 14 August 2009, a separate reporting system was established for deaths occurring outside acute hospitals. This required staff in each of the primary care trusts in England to contact every general practice in their region to ascertain any such cases. The first such report captured community deaths retrospectively from the start of the pandemic. The reporting cycle was subsequently repeated every week. Reports from acute hospitals and from primary care trusts were 
mandatory. If no deaths had occurred, a nil report was made. Deaths in acute hospitals before 7 July 2009 were ascertained through the Health Protection Agency's flu reference centres and cross checked with records held by the directors of public health in each English health region.

Six physicians working for the chief medical officer received the reports of deaths suspected to be related to pandemic $\mathrm{A} / \mathrm{H} 1 \mathrm{~N} 1$. They made direct contact with the responsible senior physician in the organisation reporting a death. They collected a standard information set from this physician (box). The American Society of Anesthesiologists (ASA) scale was used to describe the patient's general health before the onset of influenza. ${ }^{14}$

A confirmed death was defined as related to pandemic A/H1N1 if either or both of the following criteria were met: pandemic $\mathrm{A} / \mathrm{H} 1 \mathrm{~N} 1$ infection recorded on any part of a patient's death certificate (or synonym, such as "swine flu," "H1N1 pneumonia," "H1N1 virus," or other phrase clearly referring to pandemic $\mathrm{A} / \mathrm{H} 1 \mathrm{~N} 1$ in the clinical circumstances) or pandemic A/H1N1 infection confirmed by laboratory testing, either before or after death.

While the number of cases of pandemic A/H1N1 in England was small, the Health Protection Agency ascertained numbers from laboratory testing of all known suspected cases. On 15 July, the agency started weekly estimation of incident case numbers using two primary care surveillance networks. ${ }^{15}$ Estimates date back to 2 June 2009. Before this there were 225 confirmed cases in England. ${ }^{16}$ Consultation rates for influenza-like illness were recorded by the QSurveillance National Surveillance System. This captures electronic clinical record data for about 20 million patients in England registered with a general practitioner. ${ }^{17}$ The Royal College of General Practitioners and Health Protection Agency's regional microbiology network sentinel surveillance scheme estimated positivity rates of pandemic $\mathrm{A} / \mathrm{H} 1 \mathrm{~N} 1$ based on laboratory testing of a sample of patients with influenza-like illness, by region and by age group. To estimate case numbers for the whole of England, rates were multipled by consultation rates for influenza-like illness and scaled up with the most recent population estimates from the Office

Data collected for every reported death

Unique patient identifier (NHS number or hospital number)

Hospital or primary care trust

Demographics (age/sex)

Results of microbiological tests for pandemic A/H1N1

Cause of death reported on death certificate

Time course of illness (date of symptom onset, hospital admission, intensive care admission, start of of antiviral drugs)

Pre-morbid health status (ASA grade)

Underlying medical conditions listed by organ system

Malignancy, immunosuppresion, and pregnancy (directly sought risk factors) for National Statistics. The estimate was further scaled up to account for the proportion of individuals with symptomatic pandemic A/H1N1 who did not consult their general practitioner. This proportion was taken to be $50-80 \%$.

On 23 July 2009, the National Pandemic Flu Service (NPFS) was activated in England. This is a telephone and internet based service. It provides treatment advice with a standardised algorithm, and, when appropriate, authorises individuals to obtain antiviral drugs from a local collection point. The Health Protection Agency's method of estimation therefore changed from this date. The number of individuals authorised by the flu service to collect antiviral drugs was multiplied by positivity rates of pandemic $\mathrm{A} / \mathrm{H} 1 \mathrm{~N} 1$ derived from a sample of these individuals. This provided an estimated number of true positive cases. This weekly estimate was added to the weekly estimate derived from primary care surveillance. The two were scaled up to account for those individuals with symptomatic infection who neither consulted their general practitioner nor used the flu service. This proportion was estimated at 30-70\%. Hence, age specific estimates of the total number of incident symptomatic cases in the population were made on a weekly basis.

We used the estimates of case numbers and the demographic information gathered about deaths to calculate age specific case fatality rates. To account for the lag between onset of symptoms and death, ${ }^{18}$ we used the cumulative number of cases until the date two weeks before 8 November 2009. Two weeks is the approximate time period observed between onset of symptoms and death. Sensitivity analyses were performed to test the impact of censoring at one week and four weeks.

The Health Protection Agency's upper and lower estimates for the cumulative number of cases by age were used to calculate lower and upper estimates for the case fatality rates. A 95\% confidence interval was calculated around these estimates to account for the uncertainty around the observed number of deaths. ${ }^{19}$ The case fatality ranges we have presented refer to the upper 95\% confidence limit of the upper estimate of the case fatality rate and the lower $95 \%$ confidence limit of the lower estimate of the case fatality rate. We used mid-range population estimates for England from the Office for National Statistics ${ }^{20}$ to calculate the cumulative incidence of cases and the population risk of death.

We determined whether the dead patient would have been eligible for the current (phase 1) vaccination programme in England based on their age and underlying conditions. ${ }^{2122}$ The Department of Health has estimated that 9.31 million people in England are eligible. We estimated the length of stay in hospital and intensive care units by subtracting the date of admission to hospital or intensive care from the date of death

In England all deaths are recorded on a standard death certificate, which distinguishes between direct causality and contributory factors. Part I of the certificate records diseases or conditions directly leading to death in a causal chain with up to three elements, where 


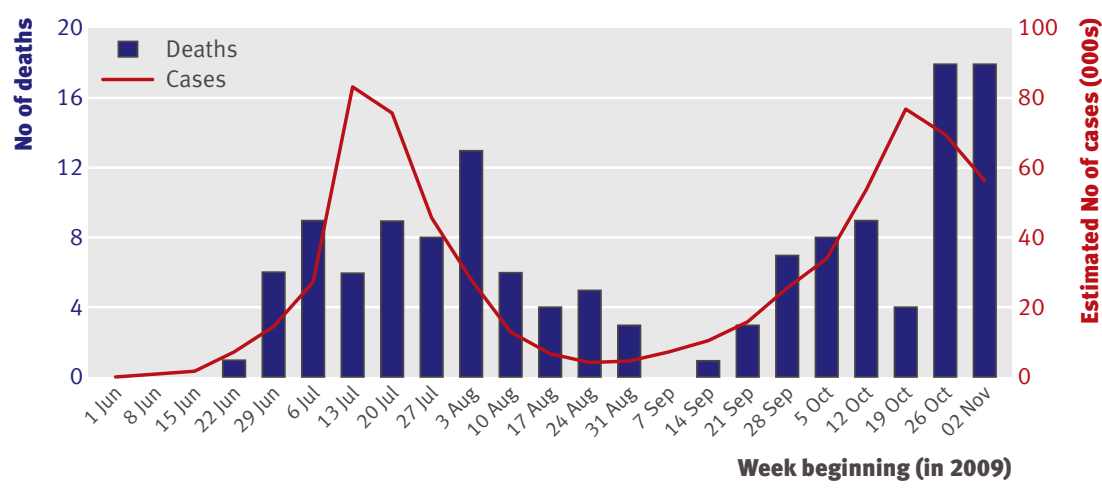

Fig 1 | Weekly estimated incidence of pandemic A/H1N1 cases (mid-range estimates) and confirmed deaths in England (source: Health Protection Agency)

$1 \mathrm{a}$ is the disease or condition directly leading to death, $1 \mathrm{~b}$ is a disease or condition leading to $1 \mathrm{a}$, and $1 \mathrm{c}$ is a disease or condition leading to $1 \mathrm{~b}$. Part II records other relevant conditions contributing to the death but not related to the disease or condition causing it. Death certificates were also analysed according to the methods of ICD-10 (international classification of diseases, 10th revision), ${ }^{23}$ used nationally and internationally to produce national mortality statistics. ${ }^{24}$ This determines an "underlying cause of death" from the causal chain and contributing conditions reported on the death certificate.

\section{RESULTS}

Initial reports of 208 deaths between 1 June and 8 November 2009 were received. Of these, 138 met the case definition as being related to pandemic $\mathrm{A} / \mathrm{H} 1 \mathrm{~N} 1$. The others were excluded from analysis because the initial clinical suspicion was not borne out by investigation and hence the case definition was not met $(\mathrm{n}=56)$ or because they did not yet fulfil the case definition but death certification or results of postmortem tests were outstanding $(\mathrm{n}=14)$.

An estimated 540000 people (range 240000$1100000)$ in England had symptomatic pandemic $\mathrm{A} / \mathrm{H} 1 \mathrm{~N} 1$ infection in the study period. With this denominator, the case fatality rate was 26 (11-66) deaths per 100000 cases. On a general population basis over the same period, there were $1100(400$
2200) cases per 100000 people and 2.7 (95\% confidence interval 2.2 to 3.2 ) deaths per million (table 1 ). Fig 1 shows the number of deaths occurring in each week and the mid-point estimate of case numbers. The time distribution of cases follows a classic epidemic curve, with a peak in July, and a second wave in October and November. The time distribution of deaths is similar, with deaths in the first wave peaking two to three weeks after the peak of cases.

A sensitivity analysis censoring cases one week before death yielded a similar case fatality rate of 22 (range 9-56) deaths per 100000 cases. Censoring at four weeks yielded a case fatality rate of 34 (14-90) deaths per 100000 . If we included all the 14 deaths currently under investigation, censoring at two weeks, the case fatality would rise to 28 (12-72).

\section{Demographic and clinical characteristics}

Patients who died ranged in age from 0 to 88 (median 39 , interquartile range 17-57). Case fatality rates varied between age groups (table 1 ). The $\geq 65$ age group had the lowest estimated incidence rate but the highest case fatality rate. Conversely, those aged 5-14 and 15-24 had the highest estimated incidence rates and the lowest estimated case fatality rates. There was no significant difference in the risk of death between males (3.0 deaths per million) and females (2.4 deaths per million) (Pearson $\chi^{2}=1.7, \mathrm{df}=1, \mathrm{P}=0.22$ ).

Before contracting pandemic A/H1NI, over a third of those who died were either previously healthy (ASA grade one, 19\%, 26/138) or had mild systemic disease that did not limit their activity (ASA grade two, 17\%, 24/138). Two thirds had severe (ASA grade three, $33 \%, 46 / 138$ ) or incapacitating (ASA grade four, $30 \%, 42 / 138)$ underlying systemic disease. Patients at the extremes of age $(<5$ and $\geq 65)$ had poorer pre-morbid health as assessed by ASA grade (fig 2).

Patients who died had a median of two long term conditions or risk factors ( 26 had no risk factors or long term conditions, 32 had one, 34 had two, 31 had three, 7 had four, 4 had five, 2 had six, and 2 had seven). Chronic respiratory disease and neurodevelopmental disorders were the most commonly reported long term conditions (table 2). The median age of patients was 8 (interquartile range $2-19, \mathrm{n}=25$ ) in those with a

Table 1 |Age specific indices of incidence of and mortality from pandemic A/H1N1 in 2009. All population and case estimates rounded to nearest 1000

\begin{tabular}{|c|c|c|c|c|c|c|c|c|}
\hline \multirow[b]{2}{*}{$\begin{array}{l}\text { Age group } \\
\text { (years) }\end{array}$} & \multirow[b]{2}{*}{$\begin{array}{l}\text { Population* } \\
\text { (1000s) }\end{array}$} & \multicolumn{2}{|c|}{ Cases (estimated) } & \multicolumn{3}{|c|}{ No of deaths } & \multirow[b]{2}{*}{$\begin{array}{l}\text { Case fatality rate } \\
\text { deaths per } 100000 \\
\text { cases (range) }\end{array}$} & \multirow[b]{2}{*}{$\begin{array}{l}\text { Population risk of death } \\
\text { deaths per } 1000000 \\
\text { population (exact } 95 \% \mathrm{Cl}\end{array}$} \\
\hline & & No (range) (1000s) & $\begin{array}{c}\text { Cumulative } \\
\text { incidence per } \\
100000 \text { population }\end{array}$ & Total & Male & Female & & \\
\hline$<1$ & 641 & $7(3-13)$ & 1000 & 2 & 1 & 1 & $30(2-260)$ & 3.1 (0.3 to 11.3$)$ \\
\hline $1-4$ & 2398 & $26(12-53)$ & 1100 & 7 & 3 & 4 & $27(3-120)$ & 2.9 (1.1 to 6.1$)$ \\
\hline $5-14$ & 5961 & $187(86-381)$ & 3100 & 20 & 7 & 13 & $11(3-36)$ & $3.4(2.0$ to 5.2$)$ \\
\hline $15-24$ & 6812 & $144(67-297)$ & 2100 & 17 & 8 & 9 & $12(3-40)$ & 2.5 (1.4 to 4.0$)$ \\
\hline $25-44$ & 14460 & $125(58-297)$ & 850 & 37 & 21 & 16 & $30(10-88)$ & 2.6 (1.8 to 3.5$)$ \\
\hline $45-64$ & 12661 & $45(21-92)$ & 350 & 29 & 21 & 8 & $65(21-200)$ & 2.3 (1.5 to 3.3) \\
\hline$\geq 65$ & 8159 & $3(1-5)$ & 30 & 26 & 14 & 12 & $980(300-3200)$ & $3.2(2.0$ to 4.7$)$ \\
\hline All ages & 51092 & $536(247-1097)$ & 1100 & 138 & 75 & 63 & $26(11-66)$ & 2.7 (2.2 to 3.2$)$ \\
\hline
\end{tabular}

*From Office for National Statistics mid-population estimates 2007. 
neurodevelopmental disorder, $30.5(20-47, \mathrm{n}=15)$ in those with asthma, and $64(48-74, \mathrm{n}=13)$ in those with COPD (chronic obstructive pulmonary disease). Of all those who died, $67 \%(92 / 138)$ fell into one of the risk categories eligible for the first phase of vaccination in England. The population risk of death for those falling into a vaccination group (9.9 per million people) was nine times that for those not in an at risk group (1.1 per million people, Pearson $\left.\chi^{2}=217, \mathrm{df}=1, \mathrm{P}<0.001\right)$. Those who were aged $\geq 65$ were more likely to fall into a priority group for vaccination than those outside this age group $(24 / 26 v 68 / 112, \mathrm{P}=0.002$, Fisher's exact test).

\section{Time course of illness and treatment}

In patients for whom a date of onset of symptoms was stated, death occurred a median of 12 days (interquartile range 5-19 days, $\mathrm{n}=114$ ) after influenza-like symptoms began. A total of 125 patients were admitted to hospital, including one patient discharged who subsequently died in the community. A further four patients died in the ambulance or on arrival at hospital. The remainder $(n=9)$ died in the community, having been solely cared for in the community.

In those admitted to hospital with pandemic A/H1N1, symptoms started a median of three days before admission (1-5 days, $\mathrm{n}=111$ ). Two patients developed influenza-like symptoms while already in hospital. The date of onset of symptoms was missing or unclear for 12 patients admitted to hospital. After the exclusion of four patients (two with hospital acquired influenza, one discharged before death, and one with date of admission missing), patients spent a median of eight days in hospital (3-14 days, $n=121$ ). Most patients admitted to hospital (82\%, 103/125), were treated in an intensive care unit at some stage, dying a median of six days (2-14 days, $n=103$ ) after admission to the unit.

\section{Use of antiviral drugs}

Of those who died, $78 \%$ (108/138) were prescribed antiviral drugs. In the 94 for whom a date of symptoms was reported, patients started taking the drugs a

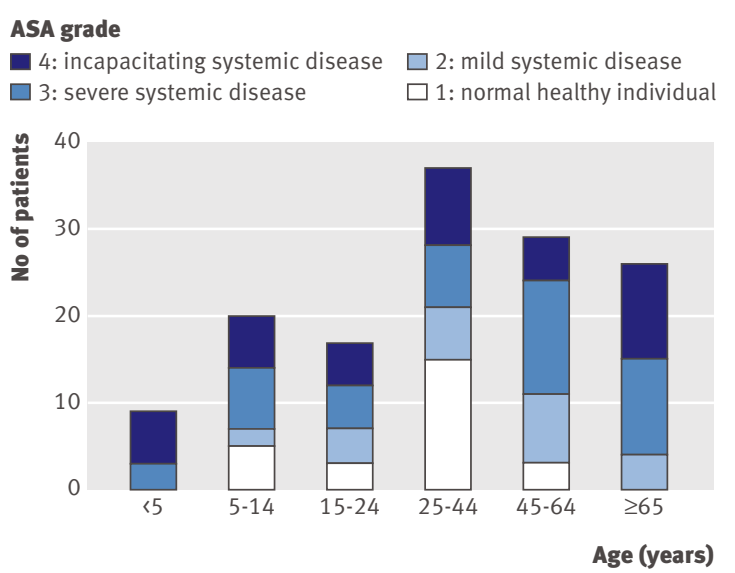

Fig 2 Age and pre-morbid health of patients who died from causes related to pandemic $\mathrm{A} / \mathrm{H} 1 \mathrm{~N} 1$ median of five days after symptoms began (interquartile range 2-8 days). Of those admitted to hospital, $9 \%(11 / 125)$ had started taking antiviral drugs before

Table 2 | History of long term conditions and other risk factors among those dying from pandemic $A / H 1 N 1$. Numbers in parentheses indicate number with single long term condition or risk factor

\begin{tabular}{|c|c|}
\hline & No of patients \\
\hline \multicolumn{2}{|l|}{ Respiratory: } \\
\hline Asthma & $15(3)$ \\
\hline COPD & $13(1)$ \\
\hline Scoliosis & $6(0)$ \\
\hline Restrictive disease & $5(0)$ \\
\hline Bronchiectasis & $4(0)$ \\
\hline Tracheostomy & $2(0)$ \\
\hline Other & $6(0)$ \\
\hline \multicolumn{2}{|l|}{ Cardiac: } \\
\hline Hypertension & $13(2)$ \\
\hline Ischaemic cardiovascular disease & $6(1)$ \\
\hline Heart failure & $9(1)$ \\
\hline Other & $6(0)$ \\
\hline
\end{tabular}

Endocrine:

\begin{tabular}{lc}
\hline Diabetes mellitus & $9(0)$ \\
\hline Obesity & $11(2)$ \\
\hline Hypothyroidism & $5(0)$
\end{tabular}

Haematological:

\begin{tabular}{ll}
\hline Leukaemia & $6(3)$ \\
\hline Other haematological malignancy & \\
\hline Anaemia & $6(1)$ \\
\hline Other & $2(0)$ \\
\hline Non-haematological malignancy & $5(1)$ \\
\hline Pregnancy & $5(3)$ \\
\hline
\end{tabular}

Neurological:

\begin{tabular}{lc}
\hline Cerebral palsy & $8(4)$ \\
\hline Other neurodevelopmental disorder & $17(2)$ \\
\hline Epilepsy & $4(0)$ \\
\hline Stroke & $3(0)$ \\
\hline Dementia & $3(0)$ \\
\hline Spinal muscular atrophy & $3(1)$ \\
\hline Quadriplegia & $2(0)$ \\
\hline Other & $4(0)$ \\
\hline
\end{tabular}

Gastrointestinal:

\begin{tabular}{lc} 
Chronic liver disease & $8(4)$ \\
\hline Percutaneous endoscopic gastrostomy & $8(1)$ \\
\hline Malnutrition & $3(0)$ \\
\hline Ulcerative colitis & $1(0)$ \\
\hline Other & $8(0)$ \\
\hline Renal: & $13(0)$ \\
\hline Chronic kidney disease & $3(0)$ \\
\hline Other & $7(0)$ \\
\hline Rheumatological: & $2(0)$ \\
\hline Inflammatory disorders & $19(2)$ \\
\hline Metabolic bone disease & $1(0)$ \\
\hline Immunosuppression:
\end{tabular}

$\mathrm{COPD}=$ chronic obstructive pulmonary disease. 
admission. Of those treated with antiviral drugs, 24\% $(26 / 108)$ received them within the recommended 48 hours after onset of symptoms. Greater use of antiviral drugs was observed in patients who died in acute hospitals than in those who died in the community (101/ 125 v 7/13, $\mathrm{P}=0.04$, Fisher's exact test,).

\section{Death certification}

In 11 cases the death certificate had not yet been issued because a coroner's investigation was ongoing $(8 \%$, 11/138). Table 3 reports the position of pandemic $\mathrm{A} / \mathrm{H} 1 \mathrm{~N} 1$ on the 127 death certificates issued. When we analysed all available death certificates using the ICD-10 methods used to produce mortality data, the underlying cause of $39 \%$ of deaths (49/127) would be classified as influenza.

We further analysed death certificates that recorded pandemic $\mathrm{A} / \mathrm{H} 1 \mathrm{~N} 1$ in the causal chain leading directly to death $(\mathrm{n}=74)$ (table 4). The direct cause of death was recorded as pandemic $\mathrm{A} / \mathrm{H} 1 \mathrm{~N} 1$ (or some synonym) in $43 \%$ of these cases $(32 / 74)$. In $11 \%$ of cases $(8 / 74)$ pandemic $\mathrm{A} / \mathrm{H} 1 \mathrm{~N} 1$ was the sole condition recorded on the death certificate. In most cases, the direct cause of death was a respiratory condition $(76 \%, 56 / 74)$.

\section{DISCUSSION}

By 8 November, about 1\% of England's population had had symptomatic pandemic A/H1N1 2009 infection (estimated range $0.5-2.2 \%$ ). We estimate that $0.026 \%$ (range $0.011-0.066 \%$ ) of these individuals died from causes related to this infection. Most (64\%) of those who died had severe or incapacitating underlying disease. The risk of contracting and dying from pandemic $\mathrm{A} / \mathrm{H} 1 \mathrm{~N} 1$ was nine times greater for people in one of the high risk groups currently being offered vaccination than for the rest of the population. A considerable minority of those who died, however, were largely healthy. Most of those who died received antiviral drugs, but many did not receive them within the recommended 48 hour window.

\section{Value of clinical reporting systems}

Establishing a standardised reporting and case by case investigation mechanism across a whole country's health service has enabled us to collect mortality data in a manner impossible in previous influenza pandemics and in many other countries today. It aimed to achieve as near complete ascertainment of cases as possible. Although the method did not capture deaths

\section{Table $3 \mid$ Microbiological testing and death certification of included deaths}

\begin{tabular}{lccc} 
Record of "pandemic A/H1N1" or & \multicolumn{2}{c}{ Confirmation of pandemic A/H1N1 by microbiological test } \\
\cline { 2 - 4 } synonym on death certificate & Positive result & No test conducted & Total \\
Recorded in part I (led directly to death) & 70 & 4 & 74 \\
\hline Recorded in part II (contributed to death) & 21 & 2 & 23 \\
\hline Not recorded on death certificate & 30 & NA & 30 \\
\hline $\begin{array}{l}\text { Death certificate not yet issued (coroner's } \\
\text { investigation awaited) }\end{array}$ & 11 & 6 & 11 \\
\hline Total & 132 & & 138 \\
\hline
\end{tabular}

$\mathrm{NA}=$ not applicable, does not meet case definition.
Table 4 Certification of direct cause of death in cases in which pandemic $A / H 1 N 1$ infection was recorded within causal chain leading to death

\begin{tabular}{|c|c|}
\hline Certified direct cause of death & No of cases (\%) \\
\hline Influenza & $32(43)$ \\
\hline Pneumonia & $14(19)$ \\
\hline $\begin{array}{l}\text { Acute respiratory distress syndrome } \\
\text { (ARDS) }\end{array}$ & $4(5)$ \\
\hline Pneumonia and ARDS & $1(1)$ \\
\hline Other respiratory complications & $5(7)$ \\
\hline Multi-organ failure & $13(18)$ \\
\hline $\begin{array}{l}\text { Intracranial haemorrhage (secondary to } \\
\text { anticoagulation for ECMO) }\end{array}$ & $2(3)$ \\
\hline Myocardial infarction & $1(1)$ \\
\hline Pulmonary embolism & $1(1)$ \\
\hline Myocarditis & $1(1)$ \\
\hline Total & $74(100)$ \\
\hline
\end{tabular}

$\mathrm{ECMO}=$ extracorporeal membrane oxygenation.

in independent sector hospitals, nearly all acute care in England is provided by the NHS. ${ }^{25}$ Under-reporting of deaths is possible because cases are either not recognised or not reported. Mandatory reporting systems, requiring a "nil report" in the absence of a positive daily or weekly report, were instigated to minimise this risk. Similarly, under-reporting of comorbidities is a possibility, particularly among older people, because they might have been undiagnosed or not known to the physicians caring for the patient in their terminal illness. The presence of obesity was not specifically asked for and might therefore be underreported. Inevitable delay in confirming or refuting the causation of some deaths might hamper the estimate of case fatality rate. There were, however, only 14 deaths in this category and so the effect on the estimate is not substantial.

These national reporting systems were established early in the pandemic. They were designed to be manageable for clinicians potentially faced with far greater numbers of deaths. Gathering more detailed clinical information would have been useful. Placing a high burden of reporting detailed data on busy clinicians, however, limits the accuracy of responses and the sustainability of data collection. Had we anticipated so few deaths, we might also have asked clinicians to provide information on surviving patients as controls. Our method focused on capturing key public health information. Comparisons with groups of patients who survived will be important in gaining full benefit from the data presented here.

\section{Case fatality rates in influenza pandemics}

The case fatality rate of $0.026 \%$ (range $0.011-0.066 \%$ ) computed by this analysis is lower than most estimates made so far in this pandemic but is also based on a different denominator. Most estimates have used laboratory confirmed cases in their denominator, resulting in rates of $0.1-0.9 \% .^{726-28}$ Confining the denominator to laboratory confirmed cases will provide a gross underestimate of the incidence of true 
symptomatic cases and therefore a substantial overestimate of the fatality rate for symptomatic cases. One Mexican study calculated a case fatality rate of $0.1 \%$, but the denominator was restricted to patients presenting to primary care. ${ }^{28}$ The validity of this denominator is questionable. Not all of these presentations would have been caused by pandemic A/H1N1, not all people with symptoms seek medical attention, and access to care might be limited in poorer areas. A much lower estimate of $0.005 \%$ (95\% confidence interval $0.003 \%$ to $0.01 \%$ ) was made in New Zealand, based on an estimate of symptomatic case numbers in the population. ${ }^{29}$ Given the move away from laboratory testing of large numbers of cases, it seems sensible that estimation of the case fatality rate should reflect this. The estimates of case fatality rates in our study have wide ranges, which reflect uncertainty about the proportion of people with symptoms who do not seek medical attention. If this proportion is higher than thought, our case fatality rates might be an overestimate. This proportion might have changed over time as public attitudes to the pandemic have evolved. The approach of using an estimate of total case numbers is subject to greater uncertainty than solely counting laboratory confirmed cases. As a measure, however, it should provide a more meaningful estimate of the case fatality rate among the symptomatic population as a whole.

Our estimate of case fatality rate compares favourably with those in the three 20th century influenza pandemics. The rate in the 1918-9 H1N1 pandemic was $2-3 \%$. Rates in the subsequent pandemics (1957-8 and 1967-8) were in the order of $0.2 \% .^{30}$ Estimates of numbers of deaths from previous pandemics are probably less reliable than current estimates, being based only on statistical methods and death certification. Laboratory confirmation of influenza viruses was not widely available. Deaths from other circulating viruses might also have been counted in the past. Improvements in nutritional status, housing, and availability of health care might explain some of the apparent decrease in case fatality from one pandemic to the next. Since the most recent pandemic there have been major advances in intensive care medicine. In the current pandemic, large numbers of patients are being treated in intensive care units, with survival rates in excess of $80 \% .^{910}$ Many more patients might have died in England without the ready availability of critical care support, including mechanical ventilation.

Although the pandemic $\mathrm{A} / \mathrm{H} 1 \mathrm{~N} 1$ virus represents an antigenic shift of the type that characterises a pandemic, it did not result in a novel $\mathrm{H}$ and $\mathrm{N}$ code. The virus shares similarities with $\mathrm{H} 1 \mathrm{~N} 1$ influenza viruses that were circulating in the mid-20th century. The population is therefore not entirely naive to the virus, as could have been the case with a more substantial antigenic shift. This might in part explain the low fatality rates.

Our data suggest a particularly high case fatality rate among those aged $\geq 65$. Our age specific case fatality rates follow a pattern similar to the $\mathrm{J}$ shaped distribution described in the previous two pandemics $^{31}$ and in a Mexican study of the current pandemic. ${ }^{28}$ The low absolute numbers of deaths and cases, however, particularly in the very young, prevent us drawing conclusions. The 1918-9 pandemic was characterised by high case fatality additionally occurring among young healthy adults. ${ }^{32}$ There is no evidence of this from our analysis of the current pandemic.

\section{Risk groups and vaccination}

So far there have been an estimated 3000 cases of pandemic $\mathrm{A} / \mathrm{H} 1 \mathrm{~N} 1$ among the eight million people aged $\geq 65$ in England, with a case fatality rate of $1.0 \%$. This group therefore has the lowest incidence rate and the highest case fatality rate. This finding is consistent with other analyses of confirmed cases and deaths during this pandemic. ${ }^{710}$ The population risk of death for this age group is not significantly different from that of any other age group. We note that almost all $(24 / 26)$ of the deaths in this age group were in people in a risk group now eligible for vaccination. The low incidence rate in this age group - seen consistently in the southern hemisphere ${ }^{33}$-might in part be because of previous exposure to strains similar to pandemic $\mathrm{A} / \mathrm{H} 1 \mathrm{~N} 1 .{ }^{34}$ Without this previous exposure, the pandemic might have caused many more deaths in this age group. If the attack rate in the older population rises over the winter, as it did in the 1957 pandemic, ${ }^{3536}$ a larger number of deaths might be anticipated. This has not, however, been observed in the southern hemisphere. ${ }^{33}$

Our series shows that a high proportion of patients $(67 \%)$ fell into one of the risk groups identified for phase one of the vaccination programme that is currently running in England. This finding supports the importance of achieving high vaccination uptake for these groups. This is consistent with the findings of a Californian study, in which $75 \%$ of patients who died had risk factors for complications of seasonal influenza. ${ }^{37}$ Other studies ${ }^{81013}$ have identified similar risk conditions, particularly asthma and other respiratory conditions and neurodevelopmental conditions. ${ }^{13}$ Obesity seems under-represented in comparison with other studies $^{810}$ and might reflect under-reporting in our study because it was not recorded as a diagnosis within the patient's hospital record. Comparisons with surviving infected patients or patients in hospital will be important in allowing the risks associated with particular underlying conditions to be further quantified.

\section{Delayed use of antiviral drugs}

While most patients received antiviral drugs, only a minority received them within the recommended 48 hour window. Similar evidence of delays in the prescription of antiviral drugs, and of less than universal use, has emerged from recent studies of hospital patients in the United States. ${ }^{813}$ An analysis of 272 inpatients with $\mathrm{A} / \mathrm{H} 1 \mathrm{~N} 1$ in the US suggests that use of antiviral drugs confers a survival benefit, 


\section{WHAT IS ALREADY KNOWN ON THIS TOPIC}

Past pandemics of influenza have produced assessments of mortality based on calculations of "excess death"; these estimates depend on death certification, which is known to be unreliable

Early reports of case fatality rates for the present $\mathrm{A} / \mathrm{H} 1 \mathrm{~N} 1$ pandemic have used laboratory confirmed cases as the denominator, likely to be a gross underestimate of incidence

\section{WHAT THIS PAPER ADDS}

The current estimated case fatality rate, using an estimate of symptomatic cases in the community as the denominator, is lower than previous estimates

In the current pandemic children have experienced the highest attack rate and the lowest case fatality rates, while older people are much less susceptible but are more likely to die when affected

particularly when they are started within two days of onset of illness. ${ }^{8}$ Although minimal, the risk of side effects associated with use of antiviral drugs and vaccination does become more important because the risk associated with the disease is also low, particularly for previously healthy people. End points other than death (such as illness requiring time off work, admission to hospital, admission to critical care) are also important. Further cost benefit analyses would be valuable although difficult, given the uncertainties of an evolving pandemic.

\section{Unreliability of death certification}

Our analysis relied on the establishment of specific national death reporting systems that are mandatory for acute NHS hospitals and primary care. Reports were made based on clinical suspicion to avoid the risk of non-reporting when test results were awaited at the time of death. Subsequent contact with the responsible clinicians enabled us to discount or to include these reports and to gather further clinical information reliably and completely.

Every year, regression models are used to estimate the number of deaths attributable to seasonal influenza, based on variation in all cause excess mortality. ${ }^{5839}$ Other analyses rely on determining cause of death from the death certificate. ${ }^{40}$ Only $39 \%$ of deaths included in this study would have been captured by this method of categorising deaths by underlying cause. The approach we used complements these statistical approaches. Their use in combination could be considered in monitoring future disease outbreaks.

\section{Conclusions}

The first influenza pandemic of the 21 st century is considerably less lethal than was feared in advance. Case fatality rates vary by age in a similar pattern to the two previous pandemics but are currently much lower. This is fortunate. The challenges of risk communication and of policy making remain.

Our findings lend support to a vaccination strategy that prioritises high risk groups. They also show that a substantial minority of deaths are occurring outside these groups. Wider population vaccination therefore merits consideration. Cost benefit analyses could further assist these decisions. These are difficult to conduct and to interpret in the uncertain context of an evolving pandemic.

We observed delayed antiviral use in most fatal cases. The value of this observation is limited by the absence of a control group, but it might be important. It suggests value in making antiviral drugs readily available to previously healthy people as well as to those at high risk. This reinforces that where countermeasures (antivirals, vaccines) are available, they should be actively deployed. A lower population impact than previous pandemics is not a justification for public health inaction when death, serious illness, and admission to hospital can be prevented.

We are grateful to the many clinicians in England who supplied the clinical information on their patients, Brian Healy (Harvard School of Public Health) for statistical advice, Gillian Perkins, Tara Fajeyisan, and Emma Stanton for managing the database, Mobasher Butt and David O'Reilly for their work establishing the project, and Andre Charlett of the Health

Protection Agency for providing estimated case numbers.

Contributors: LJD conceived the project in conjunction with his clinical advisers and has overseen the work and drafting of the manuscript. PDR BME, FECG, IEY, and OTM all had a role in designing the data collection process, collecting the data, analysing the data, and drafting the manuscript. RGP advised on analysis and critiqued the manuscript LJD is guarantor

Funding: This work was conducted as part of the public health response to pandemic influenza in England. No additional funding was sought. Competing interests: LJD is the chief medical officer for England. In this role he advises the government on public health policy, including the management of the pandemic. PDR, BME, FECG, IEY, and OTM support him in this task. All authors have completed the unified competing interest form at www.icmje.org/coi_disclosure.pdf (available on request from the corresponding author) (URL) and declare (1) no financial support for the submitted work from anyone other than their employer; (2) no financial relationships with commercial entities that might have an interest in the submitted work; (3) no spouses, partners, or children with relationships with commercial entities that might have an interest in the submitted work; and (4) no non-financial interests that may be relevant to the submitted work.

Ethical approval: This exercise was undertaken as part of a public healt surveillance programme for the pandemic. As such no explicit ethical approval was necessary or sought. This exercise was undertaken under the Health Service (Control of Patient Information) Regulations SI1438/ 2002, which provide a basis for collecting and processing data without patient consent for the purposes of communicable disease control in England

Data sharing: No additional data available.

1 Chan M. World now at start of 2009 influenza pandemic. June 2009. World Health Organization. www.who.int/mediacentre/news/ statements/2009/h1n1_pandemic phase6 20090611/en/index. html.

2 Novel swine-origin influenza $\mathrm{A}(\mathrm{H} 1 \mathrm{~N} 1)$ virus investigation team. Emergence of a novel swine-origin influenza in humans. N Engl J Med 2009;360:2605-15.

3 Health Protection Agency. Suspected cases in Scotland test positive for swine influenza. 27 April 2009. www.hpa.org.uk/web/ HPAweb\&HPAwebStandard/HPAweb_C/1240812259242.

4 Perez-Padilla R, de la Rosa-Zamboni D, Ponce de Leon S, Hernandez M, Quinones-Falconi F, Bautistia E, et al. Pneumonia and respiratory failure from swine-origin influenza $\mathrm{A}(\mathrm{H} 1 \mathrm{~N} 1)$ in Mexico. $N$ Engl J Med 2009;361:680-9.

5 Mook P, Pebody R, Zhao H, Ellis J, Zambon M, Fleming DM, et al. Surveillance of influenza and other respiratory viruses in the United Kingdom: October 2007 to May 2008. www.hpa.org.uk/hpr/ archives/Infections/2008/respiratory.htm\#ann0708.

6 Maudsley G, Williams EM. Inaccuracy in death certification-where are we now? J Public Health Med 1996;18:59-66.

7 Vaillant L, La Ruche G, Tarantola A, Barboza P. Epidemiology of fatal cases associated with pandemic H1N1 influenza 2009. Eurosurveillance 2009;14:1-6. 
8 Jain S, Kamimoto L, Bramley AM, Schmitz AM, Benoit SR, Loiue J, et al. Hospitalized patients with 2009 H1N1 influenza in the United States, April-June 2009. N Engl J Med 2009;361:1935-44.

9 Kumar A, Zarychanski R, Pinto R, Cook DJ, Marchall J, Lacroix J, et al. Critically ill patients with 2009 influenza $A(H 1 N 1)$ infection in Canada. JAMA 2009;302:1872-9.

10 ANZIC Influenza Investigators. Critical care services and 2009 H1N1 influenza in Australia and New Zealand. N Engl J Med 2009;361:1991-3.

11 Dominguz-Cherit G, Lapinsky SE, Macias AE, Pinto R, Espinosa-Perez L, de la Torre A, et al. Critically ill patients with 2009 influenza A(H1N1) in Mexico. JAMA 2009;302:1880-7.

12 Jamieson DJ, Honein MA, Rasmussen SA, Williams JL, Swerdlow DL, Biggerstaff MS, et al. H1N1 2009 influenza virus infection during pregnancy in the USA. Lancet 2009;374:451-8.

13 Centers for Disease Control and Prevention. Surveillance for pediatric deaths associated with 2009 pandemic influenza A (H1N1) virus infection-United States, April-August 2009. MMWR Morb Mort Wkly Rep 2009;58:941-7.

14 Saklad M. Grading of patients for surgical procedures. Anesthesiology 1941;2:281-4.

15 Health Protection Agency. Method used to estimate new pandemic (H1N1) 2009 influenza cases in England in the week 3 August to 9 August 2009. 2009. www.hpa.org.uk/web/HPAwebFile/HPAweb_C/ 1250150839845.

16 Health Protection Agency. Update on confirmed swine flu cases. 31 May 2009. www.hpa.org.uk/web/HPAweb\&HPAwebStandard/ HPAweb_C/1243771211786.

17 Health Protection Agency. QSurveillance National Surveillance System. www.hpa.org.uk/web/

HPAweb\&Page\&HPAwebAutoListName/Page/1203582641440.

18 Garske T, Legrand J, Donnelly CA, Ward H, Cauchemez S, Fraser C, et al. Assessing the severity of the novel influenza $A / H 1 N 1$ pandemic. BMJ 2009;339:b2840.

19 Clopper CJ, Pearson ES. The use of confidence or fiducial limits illustrated in the case of the binomial. Biometrika 1934;26:404-13.

20 Office for National Statistics. Population estimates for UK, England and Wales, Scotland and Northern Ireland-current datasets. www. statistics.gov.uk/statbase/Product.asp?vlnk=15106.

21 Donaldson L, Beasley C, Ridge K. The H1N1 swine flu vaccination programme 2009-2010. Department of Health, 2009. www.dh.gov. uk/en/Publicationsandstatistics/Lettersandcirculars/ Dearcolleagueletters/DH_107169.

22 NHS Information Centre. Seasonal influenza Read codes. Department of Health, 2009. www.immunisation.nhs.uk/ publications/

Seasonal_Influenza_READ_Code_Spec_12082009_v2.pdf.

23 World Health Organization. International classification of diseases and related health problems, 10th rev. WHO, 1992.

24 Mathers D, Ma Fat D, Inoue M, Rao C, Lopez AD. Counting the dead and what they died from: an assessment of the global status of cause of death data. Bull World Health Organ 2005;83:171-7.
25 Black A. The future of acute care. NHS Confederation Distribution, 2006.

26 De Silva UC, Warachit J, Waicharoen S, Chittaganpitch M. A preliminary analysis of the epidemiology of influenza $A(H 1 N 1) v$ virus infection in Thailand from early outbreak data, June-July 2009. Eurosurveillance 2009;14(31):1-3.

27 Fraser C, Donnelly CA, Cauchemez S, Hanage WP, Van Kerkhove MD, Hollingsworth TD, et al. Pandemic potential of a strain of influenza $A$ (H1N1): early findings. Science 2009;324:1557-61.

28 Echevarria-Zuno S, Mejia-Arangure JM, Mar-Obeso AJ, Grajales-Muniz C, Roboles-Perez E, Gonzalez-Leon M, et al. Infection and death from influenza $A$ H1N1 virus in Mexico: a retrospective analysis. Lancet 2009 Nov 11 epub ahead of print.

29 Baker MG, Wilson N, Huang QS, Paine S, Lopez L, Bandaranayake D, et al. Pandemic influenza A(H1N1)v in New Zealand: the experience from April to August 2009. Eurosurveillance 2009;14(34):1-5.

30 European Scientific Working Group on Influenza (ESWI). Pandemics of the 20th century. 2009. www.flucentre.org/files/Pandemics\% 20of\%20the\%2020th\%20century.pdf.

31 Luk J, Gross P, Thompson WW. Observations on mortality during the 1918 influenza pandemic. Clin Infect Dis 2001;33:1375-8.

32 Taubenberger JK, Morens DM. 1918 influenza: the mother of all pandemics. Emerg Infect Dis 2006;12:15-22.

33 Baker MG, Kelly H, Wilson N. Pandemic H1N1 influenza lessons from the southern hemisphere. Eurosurveillance 2009;14(42):pii=19370. www.eurosurveillance.org/ViewArticle. aspx?Articleld=19370.

34 Centers for Disease Control and Prevention (CDC). Serum crossreactive antibody response to a novel influenza $A(H 1 N 1)$ virus after vaccination with seasonal influenza vaccine. MMWR Morb Mortal Wkly Rep 2009;58:521-4.

35 Woodall J, Rowson KEK, McDonald JC. Age and Asian influenza. BMJ 1958;ii:1316-8.

36 Payne MM. Some aspects of the epidemiology of the 1957 influenza pandemic. Proc R Soc Med 1958;51:1009-18.

37 Louie JK, Acosta M, Winter K, Jean C, Gavali S, Schecther R, et al. Factors associated with death or hospitalisation due to pandemic 2009 influenza $\mathrm{A}(\mathrm{H} 1 \mathrm{~N} 1)$ infection in California. JAMA 2009;302:1896-902.

38 Noble GR. Epidemiological and clinical aspects of influenza. In Beare AS, ed. Basic and applied influenza research. CRC Press, 1982:11-50.

39 Serfling RE. Methods for current statistical analysis of excess pneumonia-influenza deaths. Public Health Reports 1963;6:494-506.

40 Office for National Statistics. Mortality statistics deaths registered in 2008. Office for National Statistics, 2009. http://www.statistics.gov. uk/statbase/Product.asp?vlnk=15096

Accepted: 30 November 2009 